\title{
INFLUÊNCIA DE EXTRATO DE LEVEDURAS SOBRE PRODUTOS DE FERMENTAÇÃO INTESTINAL E CARACTERÍSTICAS FECAIS DE CÃES
}

(Influence of yeast extract on intestinal fermentation products and fecal characteristics of dogs)

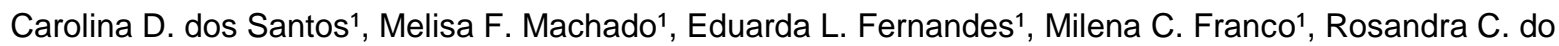
Nascimento ${ }^{1}$, Ananda P. Félix ${ }^{1}$

1Departamento de Zootecnia - UFPR

E-mail: cadallagassa@gmail.com

Resumo: Objetivou-se avaliar os efeitos da inclusão de $2 \%$ de extrato de leveduras sobre os produtos de fermentação intestinal e características fecais de cães adultos. Foram avaliadas duas dietas contendo níveis de $0 \%$ e $2 \%$ de extrato de leveduras. As dietas foram fornecidas durante 25 dias a 16 cães adultos, distribuídos inteiramente ao acaso $(n=8)$. As fezes foram colhidas nos últimos 5 dias experimentais para determinação dos produtos de fermentação intestinal e características fecais. A dieta contendo $2 \%$ de extrato de leveduras proporcionou aumento no escore fecal e na concentração de ácido acético $(P<0,05)$. Os resultados indicam que a adição de $2 \%$ de extrato de leveduras aumenta a consistência e o ácido acético das fezes de cães.

Palavras-chave: Ácido acético, ácidos graxos de cadeia curta, escore fecal.

Abstract: The objective of this study was to evaluate the effects of the inclusion of $2 \%$ of yeast extract on intestinal fermentation products and fecal characteristics of adult dogs. Two diets containing $0 \%$ and $2 \%$ yeast extract levels were evaluated. Diets were given for 25 days to 16 adult dogs, distributed entirely at random $(n=8)$. Stool was collected in the last 5 experimental days for determination of intestinal fermentation products and fecal characteristics. The diet containing $2 \%$ yeast extract provided an increase in fecal score and acetic acid concentration $(P<0.05)$. The results indicate that the addition of $2 \%$ of yeast extract increases the consistency and acetic acid of the faeces of dogs.

Keywords: acetic acid, short chain fatty acids, fecal score

Introdução: O extrato de leveduras possui composição rica em diversos nutrientes, como, proteínas, vitaminas do complexo B, enzimas, ácidos graxos voláteis e minerais quelatados. Seu uso já é bem difundido na nutrição de monogástricos, porém não há muitos estudos sobre o extrato de leveduras na dieta de cães. 0 objetivo foi avaliar a influência do extrato de leveduras sobre produtos de fermentação intestinal e características fecais de cães.

Material e Métodos: Foram utilizados 16 cães adultos da raça beagle, distribuídos em delineamento inteiramente casualizado, totalizando oito repetições por dieta. Foram avaliadas duas dietas ( $0 \%$ e $2 \%$ de extrato de leveduras). Seguiu-se 0 protocolo de coleta total de fezes recomendado pela AAFCO (2004). As fezes foram analisadas quanto à produção total, matéria seca, $\mathrm{pH}$, amônia, escore fecal $(1=$ fezes líquidas a 5 = fezes secas) e ácidos graxos de cadeia curta (AGCC) e ramificada (AGCR), analisados por cromatografia gasosa (ERWIN, 1961). Os resultados foram testados quanto à normalidade (Shapiro-Wilk). Posteriormente, os 
dados paramétricos foram submetidos ao teste t-Student e as variáveis não paramétricas ao teste de Wilcoxon, ambos considerando $\mathrm{P}<0,05$.

Resultados e Discussão: A inclusão de $2 \%$ do extrato de leveduras proporcionou aumento do escore fecal dos cães (Tabela 1, $P<0,05)$. Estes achados não corroboram aos verificados nos estudos de STRICKLING et al. (2000) e ZENTEK et al. (2002), que não encontraram alteração na produção e no escore fecal usando mananoligosacarídeos (MOS) em cães. O ácido acético, apresentou aumento $(\mathrm{P}<0,05)$ com a inclusão de $2 \%$ de extrato de leveduras na dieta. Ao contrário do encontrado por ZENTEK et al. (2002), que não encontraram diferença quanto aos AGCC e STRICKLING et al. (2000), que observaram somente redução no butirato. $O$ ácido acético é rapidamente absorvido como ácido não dissociado através da membrana luminal por difusão passiva, processo que envolve troca de íons de sódio e hidrogênio pela membrana, fazendo com que o intestino grosso absorva maior quantidade de água do bolo fecal, o que justificaria o aumento do escore fecal.

Tabela 1- Médias das características fecais de cães alimentados com dietas contendo ou não extrato de leveduras.

\begin{tabular}{|c|c|c|c|c|}
\hline & \multicolumn{2}{|c|}{ Extrato de leveduras (\%) } & \multirow{2}{*}{ EPM } & \multirow{2}{*}{$\mathrm{P}$} \\
\hline & 0 & 2 & & \\
\hline $\mathrm{Ph}$ & 6,711 & 6,693 & 0,089 & 0,492 \\
\hline Matéria seca (\%) & 33,65 & 35,08 & 0,004 & 0,365 \\
\hline Produção fecal & 0,63 & 0,63 & 0,02 & 0,950 \\
\hline Amônia (\%) & 0,055 & 0,067 & 0,0043 & 0,227 \\
\hline Escore Fecal & 3,6 & 3,8 & - & 0,044 \\
\hline
\end{tabular}

EPM = erro padrão da média; Produção fecal $=\mathrm{g}$ fezes produzidas na matéria natural $/ \mathrm{g}$ matéria seca consumida/dia; Valores de $\mathrm{P}$ obtidos pelo teste t-Student $(\mathrm{P}<0,05)$; Escore fecal analisado por Wilcoxon ( $\mathrm{P}$ $<0,05)$, sendo 1 = líquido $5=$ secas.

Tabela 2 - Médias (Mmol) dos ácidos graxos de cadeia curta (AGCC) e ramificada (AGCR) das fezes de cães alimentados com dietas contendo 0 ou $2 \%$ de extrato de leveduras.

\begin{tabular}{ccccccccc}
\hline & & & & & & & Total & Total \\
Item & Acético & Propionico & Butirico & Isobutirico & Isovalerico & Valerico & AGCC & AGCR \\
\hline $0 \%$ & 29,083 & 15,419 & 4,368 & 0,621 & 0,827 & 0,361 & 49,194 & 1,824 \\
$2 \%$ & 33,297 & 17,505 & 4,432 & 0,534 & 0,698 & 0,405 & 53,940 & 1,768 \\
EPM & 1,669 & 1,164 & 0,363 & 0,045 & 0,084 & 0,065 & 2,924 & 0,197 \\
P & 0,016 & 0,131 & 0,902 & 0,134 & 0,230 & 0,430 & 0,161 & 0,943 \\
\hline
\end{tabular}

EPM= erro padrão da média; $\mathrm{P}<0,05$ pelo teste t-Student.

Conclusão: A inclusão de $2 \%$ do extrato de leveduras aumenta o escore fecal de cães e a produção de ácido acético, melhorando a consistência fecal.

Referências: AAFCO., 2004. Dog and cat nutrient profiles. Official Publications of the Association of American Feed Control Officials Incorporated. Oxford, IN, USA. ERWIN, E.S. et al. Volatile fatty acid analyses of blood and rumen fluid by gas chromatography. Journal of Dairy Science, v.44, p.1768-1771, 1961.

STRICKLING, J.A. et al. Evaluation of oligosaccharide addition to dog diets. Animal Feed Science and Technology, v.86, p.205-219, 2000.

ZENTEK, J. et al. Intestinal effects of mannanoligosaccharides, transgalactooligosaccharides, lactose and lactulose in dogs. Journal of Nutrition, v.132, 1682S-1684S, 2002. 